\title{
Pharmaceutical Formulation and Biochemical Evaluation of Atorvastatin Transdermal Patches
}

\author{
Tamer M. Shehata ${ }^{1,2,}$ Omar M.M. Mohafez ${ }^{1,3,}$ Hamza N. Hanieh ${ }^{4}$ \\ ${ }^{1}$ College of Clinical Pharmacy, King Faisal University, Ahsaa, SAUDI ARABIA. \\ ${ }^{2}$ Department of Pharmaceutics and Industrial Pharmacy, Faculty of Pharmacy, Zagazig University, EGYPT. \\ ${ }^{3}$ Department of Biochemistry, Faculty of Pharmacy, Al-Azhar, Assiut University, EGYPT. \\ ${ }^{4}$ Department of Biological Sciences, Faculty of Science, King Faisal University, Ahsaa, SAUDI ARABIA.
}

\begin{abstract}
Atorvastatin is a lipid lowering agent and widely used to treat hypercholestermia. However following oral administration, the bioavailability of the drug is only $12 \%$ due to extensive first pass metabolism. The aim of the current research was to formulate ATO- transdermal patches utilizing various polymers combinations. Hydroxypropyl methylcellulose with either eudragit RS100 or Polyvinylpyrrolidone were mixed in different ratios, in presence of polyethylene glycol 400 as plasticizer. The patches were prepared by solvent evaporation method. Physicomechanical parameters such as, drug content, patch thickness, tensile strength, moisture loss and moisture gained were evaluated. Additionally drug excipient compatibility was assessed by FTIR and DSC. In vitro drug release was measured in phosphate buffer $\mathrm{pH} 7.4$ at $37^{\circ} \mathrm{C}$. Finally, biochemical evaluation of the best formulae was evaluated on hyperlipidemic-induced rats. The results indicated that, Hydroxypropyl methylcellulose: Polyvinylpyrrolidone in a ratio of 3:1 showed the most appropriate physicomechanical characters with confirmed physical and chemical drug-polymer compatibility. In addition, the in-vitro experiment showed enhanced atorvastatin release over $24 \mathrm{hr}$. The pharmacological evaluation of F2 formula indicated a significant hypolibedimic effect compared to orally administered atorvastatin. The results revealed that, atorvastatin transdermal patch could be considered as promising drug delivery system for hyperlipidemic patients.
\end{abstract}

Key words: Atorvastatin, Patches, Polymers, FTIR, DSC, Hyperlipidemia.

\section{INTRODUCTION}

Hyperlipidemia is one of the greatest risk factors contributing to the prevalence and severity of coronary heart diseases (CHDs). ${ }^{1}$ Hyperlipidemia is characterized by elevated serum total cholesterol (TC), low density lipoprotein (LDL) and decreased high density lipoprotein (HDL) levels. Hypercholesterolemia and hypertriglyceridemia are closely related to ischemic heart disease and considered as a primary cause of death. ${ }^{2}$ One of the best choices for treatment of hyperlipidemia is atorvastatin (ATO), which is a statin analogue used as lipid lowering-agent and widely used to treat hypercholesterolemia and it is a potent inhibitor of HMG-CoA reductase. ATO belongs to the Biopharmaceutical
Classification System-II (BCS-II) (i.e., drug with low aqueous solubility and high permeability). ${ }^{3}$ It is insoluble in aqueous media and freely soluble in methanol. It has molecular weight 1209.42 and melting point ranged between $159^{\circ} \mathrm{C}$ and $160^{\circ} \mathrm{C}$. It is weakly acidic with Pka 4.46, hydrophobic and has aqueous solubility of $0.63 \mathrm{mg} / \mathrm{L}$. Following oral administration ATO has extensive first pass metabolism resulting in poor oral bioavailability $(12 \%){ }^{4}$ ATO is available commercially as $10 \mathrm{mg}, 20 \mathrm{mg}, 40 \mathrm{mg}$, and $80 \mathrm{mg}$ orally administered tablets. However, several drawbacks raised following oral administration of ATO, such as, muscle pain accompanying the administration of
Submission Date: 01-05-2017; Revision Date: 15-06-2017; Accepted Date: 25-09-2017

DOI: 10.5530/ijper.52.1.6 Correspondence: Tamer M. Shehata, College of Clinical Pharmacy, King Faisal University, Ahsaa, SAUDI ARABIA. Phone no: 0966564787190; E-mail: tshehata@kfu.edu.sa, tamershehata@zu.edu.eg

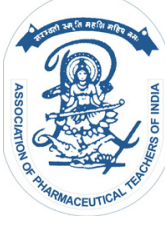

www.ijper.org 
large doses, stomach upset and gastric irritation. ${ }^{5}$ Therefore, exploring alternative route of administration of ATO, could enhance the patient compliance by reducing the previously mentioned side effects. Transdermal drug delivery system (TDDS) could be considered as superior alternative route to oral drug delivery. TDDS has been designed to provide controlled continuous delivery of drugs via the skin to the systemic circulation and provides a means to sustain drug release. ${ }^{6}$ TDDS can avoid several drawbacks of oral administration such as, first-pass elimination by the liver, hydrolytic effect of GIT juices and GIT irritation caused by drugs. Patches are considered as one of the best formulations belongs to TDDS. Patches can be defined as a flexible, medicated adhesive of varying size containing one or more drug substances that is placed on the skin to deliver a specific dose into systemic circulation. ${ }^{7}$ The aim of this study was to formulate ATO in suitable transdermal patches as an alternative route of drug administration having sustained effect, enhancing patient compliance and avoiding oral administration drawbacks. Physicomechanical evaluation, physical and chemical compatibility and in vitro drug release will be evaluated. Finally, pharmacological activity of the best formulae will be assessed on hyperlipidemic induced animal.

\section{Materials and Methods}

Atorvastatin calcium, Hydroxypropyl methylcellulose HPMC (50 cP), Eudragit RS 100 and Polyvinylpyrrolidone (PVP) 30K, kindly supplied by Saudi Pharmaceutical Industries \& Medical Appliances Corporation (SPIMACO), KSA. Cellulose membrane, M.W., cut off 12000-14000 (Fisher Scientific; Pittsburgh, PA, U.S.A). Total cholesterol, triglycerides, and HDL-cholesterol kits were purchased from United Diagnostic Industry, Dammam, KSA. Cholesterol powder was purchased from Sigma Chemicals, St. Louis, MO, USA. Sodium cholate obtained from Himedia Laboratories. The remaining chemicals used were analytical grade and obtained from local distribution agent in KSA.

\section{Preparation of ATO loaded patches}

In this study, ATO loaded patches were prepared by solvent evaporation method. Glass plates with diameter of $7 \mathrm{~cm}$ and total area of $38.5 \mathrm{~cm}^{2}$ were used. The polymers were accurately weighed and dissolved in $8 \mathrm{ml}$ of dichloromethane: methanol (4:1), by the aid of mechanical stirrer $50 \mathrm{rpm}$ for 10 minutes to form a clear solution, and kept a side. ATO, PEG 400 and dimethyl sulfoxide (DMSO) were added to the above clear solution and mixed for 10 min using mechanical stirrer. The resulted uniform solution was poured into the glass plate and dried at $40{ }^{\circ} \mathrm{C}$ in the hot air oven for $24 \mathrm{hr}$. The dried patches was taken out, wrapped in aluminum foil and stored in a desiccator for next studies. Compositions of different formulations are shown in Table (1).

\section{Evaluation of transdermal patches Physicomechanical evaluation \\ Physical examination}

Transdermal patches were visually inspected for their color, clarity, flexibility, homogeneity and smoothness. Unfortunately, formulations F4 and F8 were not formed, as they were very dry and very thin, that could be attributed to lower HPMC percentage.

\section{Thickness}

A digital caliper (Electronic digital Caliber, AHK, Germany) was used to measure the thickness at three different positions on the same patch of each formulation. ${ }^{8}$

\section{Folding endurance}

A strip of specific area $2 \mathrm{~cm} \times 2 \mathrm{~cm}\left(4 \mathrm{~cm}^{2}\right)$ was folded at the same place several times until a visible crack was observed and then broke. The value of folding endurance is the number of times the patch could be folded without breaking.

\section{Tensile strength}

Universal tensile strength apparatus (Hounsfield, slinfold, Horsham, UK) was used to measure the patches' tensile strength. The test patches were cut into strips of $1 \mathrm{~cm}$ width and $6 \mathrm{~cm}$ length, and were fixed between the machine grips. Force was gradually applied till the patch broke. The tensile load of the patch was taken directly from the dial reading in $\mathrm{kg}$. Tensile strength is calculated as follows:

Tensile strength $=$ Tensile load at break $/$ Cross section area

\section{Weight uniformity}

Weight uniformity was done by weighing 3 different patches of the same formulation. All the patches, selected randomly, should be uniform in size $(1 \mathrm{~cm} \times 1 \mathrm{~cm}){ }^{10}$

\section{Moisture uptake}

$4 \mathrm{~cm}^{2}$ patches were weighed separately and kept at $80-90 \%$ relative humidity using saturated solution of potassium chloride in desiccators. ${ }^{11}$ Three days later; the patches were taken out and weighed. The percentage of moisture uptake was calculated as given below:

$\%$ Moisture uptake $=[$ Final weight - Initial weight $]$ Initial weight] x 100 


\section{Moisture loss}

$4 \mathrm{~cm}^{2}$ patches were weighed separately and kept in a desiccators containing calcium chloride at room temperature for $24 \mathrm{hr}$. The patches were weighed again after 3 days. ${ }^{12}$ The percent moisture content was calculated by following formula:

$\%$ Moisture content $=[$ Initial weight - Final weight $/$ Final weight] x 100

\section{Drug content}

A $100 \mathrm{ml}$ graduated flask containing phosphate buffer pH 7.4 was used to asses the ATO content. $1 \mathrm{~cm}^{2}$ patch was added to the flask and shaked for $4 \mathrm{hr}$ in a mechanical shaker. The resulted solution was filtered, diluted with phosphate buffer $\mathrm{pH} 7.4$ and examined for the drug content. A blank solution consisting of the placebo patches was used. The drug was estimated at $\lambda \max 246 \mathrm{~nm}$ and the drug content was calculated. ${ }^{13}$

\section{Drug-excipient compatibility studies}

Fourier transforms infrared spectroscopy (FTIR) studies:

In order to investigate any possible chemical interaction between the drug and the polymers, FTIR spectrophotometer (FTIR-800, Shimadzu, Japan) was used. ATO solely or in combination with the polymers under investigation were comprised into small discs with the aid of $\mathrm{KBr}$ and spectra were recorded in the frequency range from 4000 to $400 \mathrm{~cm}^{-1} \cdot{ }^{14}$

\section{Differential scanning calorimetry (DSC) studies}

$5 \mathrm{mg}$ of pure ATO or physical mixture of ATO and the polymers under investigation were sealed in flat-bottom aluminum pans, and the temperature increased from 25 to $300^{\circ} \mathrm{C}$ in nitrogen atmosphere at flow rate of (30 ml/min). ${ }^{14}$

\section{In vitro drug release}

A modified Franz diffusion cell with a receptor compartment capacity of $50 \mathrm{ml}$ was used for in vitro drug release studies. The donor and receptor compartment of the diffusion cell were separated by synthetic cellophane membrane. One $\mathrm{cm}^{2}$ of the formulated patches were placed over an adhesive tape, covered by the cellophane membrane and attached to glass holder. The receptor compartment of the diffusion cell were filled with phosphate buffer $\mathrm{pH}$ 7.4. The temperature was maintained at $37^{\circ} \mathrm{C}$. Two $\mathrm{ml}$ samples were withdrawn at time interval of $0.5,1,2,4,6,8,12$ and $24 \mathrm{hr}$, analyzed for drug content spectrophotometrically at $\lambda \max 246$ nm against blank. ${ }^{15}$

\section{In vivo studies}

\section{Animals}

Male Wister rats weighing ( $200 \pm 25 \mathrm{gm})$ were obtained from collage of veterinary medicine, Zagazig University, animal breeding center, Egypt and treated according to ethical committee of animal handling in Zagazig University "ECAHZU". The animals were kept in an environmentally controlled room maintained at $23 \pm 1^{\circ} \mathrm{C}$ and housed in well-ventilated large spacious polypropylene cages with $12 \mathrm{~h}$ light/dark cycle throughout the experimental period. Animals were maintained on high fat diet (standard rodent pellet diet supplemented with $8 \%$ butter, $0.2 \%$ sodium cholate and $5 \%$ cholesterol) for four weeks to prepare hyperlipidemia animal model. ${ }^{16}$

\section{Experimental design}

At the beginning of the experiment, blood samples were collected by retro-orbital sinus puncture using capillary tubes under diethyl ether anesthesia from all animals after $12 \mathrm{hr}$ fasting to determine lipid profile. Serum was separated by centrifugation at $3000 \mathrm{rpm}$ rotation for $10 \mathrm{~min}$, and the serum obtained was stored at $-20{ }^{\circ} \mathrm{C}$ until analysis. After four weeks on the high fat diet, blood samples were taken again from all animals to exclude rats having normal lipid profile. Animals were classified into five groups. Group 1 (G1) normal rats on normal diet, group 2 (G2) non treated hyperlipidemic rats, group 3 (G3) orally treated hyperlipidemic rats with $10 \mathrm{mg} / \mathrm{kg}$ ATO, group 4 (G4) received patches formulation number 2 contain $10 \mathrm{mg} / \mathrm{kg}$ ATO and group 5 (G5) received patches formulation number 2 contain $20 \mathrm{mg} / \mathrm{kg}$ ATO. The patches ware replaced every day for two weeks. Back dorsal of rats in groups G4 and G5 was removed using shaving machine first then completely cleaned by a razor as shown in Figure 3.

\section{Determination of lipid profile}

Serum levels of total cholesterol were measured by an enzymatic method based on the hydrogen peroxide produced during the oxidation of cholesterol is used in conjunction with peroxidase, 4-aminoantipyrine and phenol to form a quinoneimine dye that absorbs light which is measured. ${ }^{17}$ HDL-cholesterol determined by precipitating (LDL and VLDL) by phosphotungestic acid and magnesium chloride reagent. The HDL fraction remained in the supernatant is treated as a sample of cholesterol. Serum levels of triglycerides were determined by hydrolysis of TG by lipase. The glycerol concentration is then determined by enzymatic assay coupled with Trinder reaction that terminates in the formation of a quinoneimine dye. The amount of the dye formed, determined by its absorption at $505 \mathrm{~nm}$ is 
directly proportional to the concentration of TG present in the sample. ${ }^{18-19}$ LDL-cholesterol was calculated by the Friedwald's formula:

$$
\begin{aligned}
\text { LDL-cholesterol }= & \text { total cholesterol }-(\text { HDL-cholesterol }) \\
& -(\text { triglycerides } / 5) \cdot{ }^{20}
\end{aligned}
$$

\section{Statistical analysis}

Data were expressed as mean \pm standard deviation (SD) for five animals in each group. Statistically significant differences between the groups were determined by means of one way ANOVA followed by Turkey's multiple comparison test. In all cases probability values of $p<0.05$ were taken as statistically significant.

\section{RESULTS AND DISCUSSION}

The transdermal patches were prepared by solvent evaporation techniques, where the polymers were dissolved in the selected solvent and ATO was mixed homogenously. The visual examination was performed on ATO transdermal patches, where smooth, flexible and transparent patches were obtained.

\section{Physical and Chemical compatibilities}

The possibility of physical interaction between the ATO and the polymers under investigation were detected through DSC technology. DSC thermogram of pure ATO showed one endothermic peak at $160{ }^{\circ} \mathrm{C}$ corresponding to the melting point of the ATO as shown in Figure 1. Physical mixture of ATO, HPMC and PVP showed endothermic peaks at $157^{\circ} \mathrm{C}$ and a broad peak at $75^{\circ} \mathrm{C}$ as shown in Figure 1-A. Additionally, the physical mixture of ATO, HPMC and RS100 showed only one endothermic peak at $160{ }^{\circ} \mathrm{C}$, Figure 1-B. The previous results indicated that, the characteristic peaks of ATO appeared in the physical mixture of both formulations confirming good physical compatibility. Furthermore, the possibility of any chemical interactions among the drug and the polymers under investigation was confirmed by FTIR technique. The results obtained from pure ATO is shown in Figure 2, physical mixture of polymers with and without ATO were studied. The characteristic peaks of ATO were observed at the regions of $3360 \mathrm{~cm}^{-1}, 3250 \mathrm{~cm}^{-1}$ and $1650 \mathrm{~cm}^{-1}$, due to the $\mathrm{O}-\mathrm{H}$ stretching, $\mathrm{N}-\mathrm{H}$ stretching and the $-\mathrm{C}=\mathrm{O}$ stretch respectively. At finger print region, peaks were recognized at, $1315 \mathrm{~cm}^{-1}$ and $1215 \mathrm{~cm}^{-1}$ for C-O stretching and for $\mathrm{C}-\mathrm{N}$ stretching indicating the purity of the drug. The finger print spectrum of the drug was always present when mixing the drug with polymers under investigations. A possibility of hydrogen pond formation was observed through broaden of $\mathrm{O}-\mathrm{H}$ bond of HPMC and $\mathrm{N}-\mathrm{H}$ group of ATO as shown in Figure 2-A. The presence of RS100 did not result in significant interactions, where their characteristics peaks of ATO were always present, Figure 2-B. In conclusion, FTIR results indicated no significant interaction between drug and polymers under investigation.

\section{Physicomechanical evaluation of transdermal patches}

The physicomechanical characteristics of the prepared patches are shown in (Table 2). Thickness of patches ranged from $0.11 \pm 0.22 \mathrm{~mm}$ to $0.13 \pm 0.08 \mathrm{~mm}$ with low standard deviation indicating uniformity of the ATO patches. The weight ranged from 18.12 \pm 0.44 to $18.98 \pm 0.66 \mathrm{mg} / \mathrm{cm}^{2}$. Drug content determination ranged between $1.29 \pm 0.45$ and $1.32 \pm 0.55 \mathrm{mg} / \mathrm{cm}^{2}$ showing an even distribution of ATO in the patches. Folding endurance values were ranged between $80 \pm 11$ and $98 \pm 5$, which are sufficient for optimum flexibility and integrity of the patches. Tensile strength measurements varied between $0.19 \pm 0.22$ to $0.31 \pm 0.09 \mathrm{~kg} / \mathrm{cm}^{2}$. The value of tensile strength decreased by increasing the amounts of HPMC. The moisture absorption percentage lied between $2.12 \pm 0.51$ to $4.83 \pm 0.39 \%$, on the other hand, moisture loss percentage ranged between $6.32 \pm 0.36$ to $10.15 \pm 1.13 \%$, it is worth notice that, F1 (highest \% of HPMC) showed the highest percentage of moisture gained and moisture loss. It was reported previously that, low moisture content can help the patch to remain stable and avoid brittleness or drying during long-term storage. ${ }^{21}$

\section{In vitro release studies}

The in vitro release studies were carried out using modified Franz diffusion method to demonstrate the most proper formula capable of sustaining the drug release up to $24 \mathrm{hr}$. The percentage of ATO released from transdermal patches against timeis shownin Figure 4, theATOreleased from the prepared formulations could be arranged in ascending order as follow: $\mathrm{F} 1>\mathrm{F} 2>\mathrm{F} 3>\mathrm{F} 5>\mathrm{F} 6>\mathrm{F} 7$, with release percentage of $98.86 \%, 82.66 \%, 48.87 \%$, $44.73 \%, 43.71 \%$ and $36.51 \%$ respectively. The results indicated that the release of ATO from formulations containing PVP, F1-F3, decreased by increasing the amount of the PVP where in F1 (HPMC/PVP, 350:50), showed the highest ATO released about $98.86 \%$ after $24 \mathrm{hr}$ and F3 (HPMC/PVP, 250:150), showed reduction in ATO released about $48.87 \%$, after $24 \mathrm{hr}$. Similarly, addition of RS100 to HPMC resulted in decreasing the percentage of ATO released. As shown in Figure 4, F5 (HPMC/RS100, 350:50), showed ATO released about 44.73\% after $24 \mathrm{hr}$ and F7 (HPMC/RS100, 250:150), 


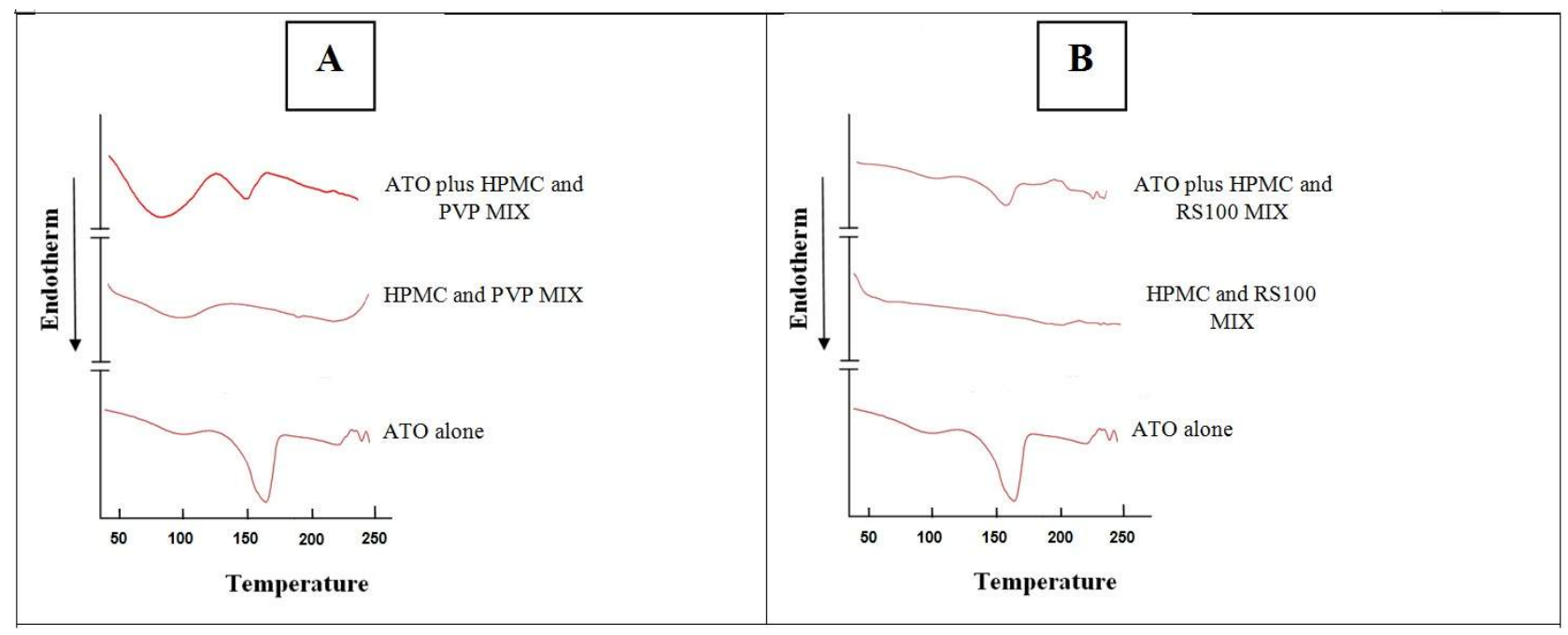

Figure 1: DSC spectra of ATO - polymers system; A: ATO-HPMC-PVP, physical mixture; B: ATO-HPMCRS100, physical mixture.
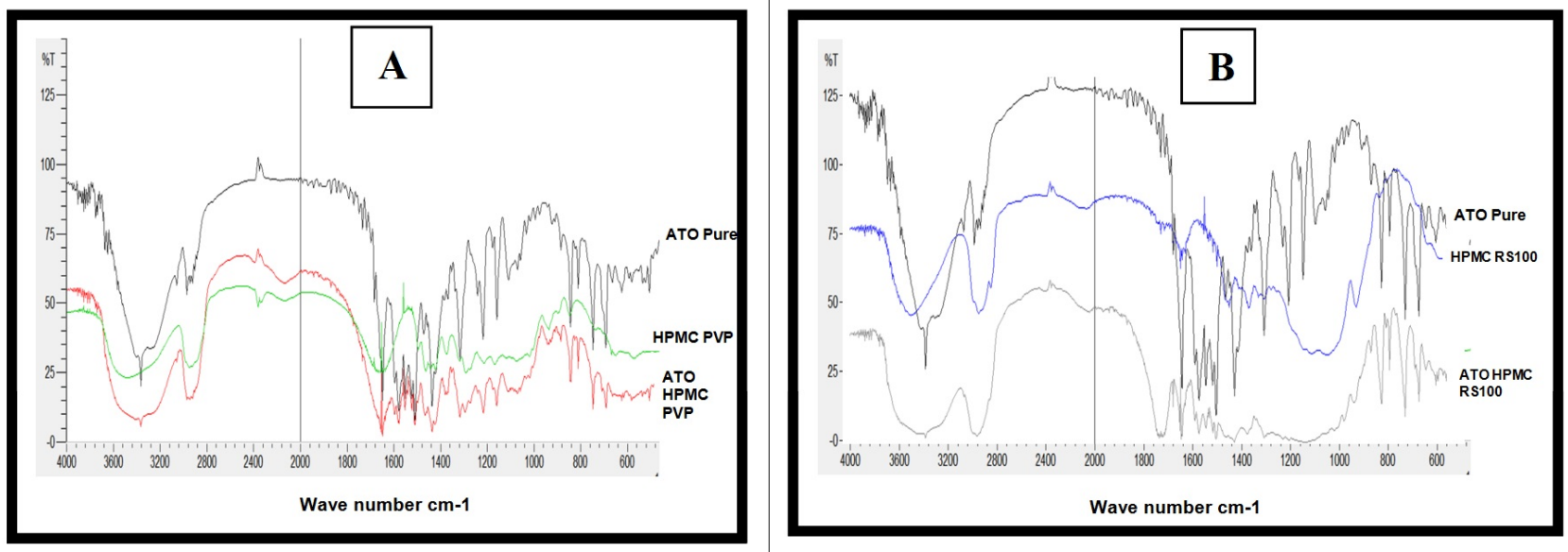

Figure 2: FTIR spectra of ATO - polymers system; 2-A: ATO-HPMC-PVP, physical mixture; B: ATO-HPMCRS100, physical mixture.

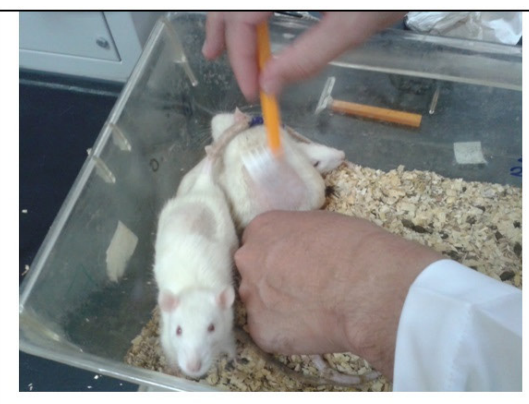

A

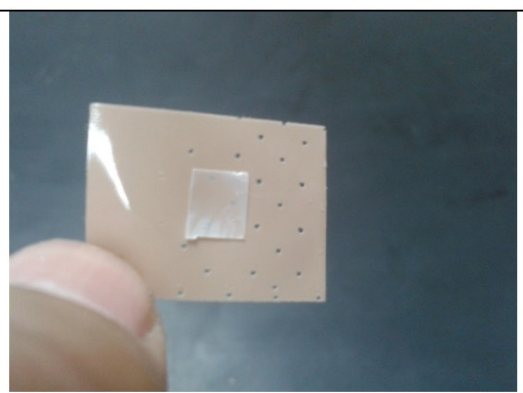

B

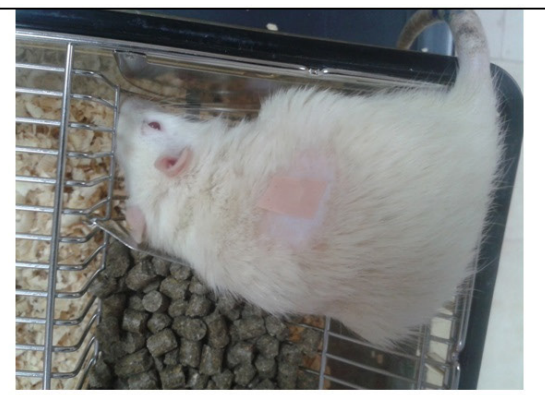

$\mathrm{C}$

Figure 3: A; animals shaving process, B; adjusted dose of ATO from transdermal patche adhered on adhesive material, and C; animal with transdermal patches fixed on the back of rats. 
showed the lowest ATO released about $36.51 \%$, after $24 \mathrm{hr}$. The previous result could be attributed to the solubility of HPMC in the diffusion medium resulting in higher partitioning of drug between hydrophilic polymer and diffusion medium. Additionally, the burst effect of PVP resulted in faster drug release of drug from patches containing PVP. On the contrary, addition of eudragit RS 100 resulted in reduction of drug release that could be attributed to low water permeability com- pared to the rest of polymers. ${ }^{8-9,22}$ According to the previous data, the optimum sustained release profiles were obtained from F2 (HPMC/PVP, 300:100). Therefore, F2 was selected for further in-vivo studies.

\section{In vivo evaluation}

In order to investigate the in vivo effect of ATO containing patches, hyperlipidemic rats were used. As shown in Table 3, four weeks on high fat diet significantly increased $(\mathrm{P}<0.001)$ the total cholesterol in comparison

\begin{tabular}{|c|c|c|c|c|c|c|c|}
\hline \multicolumn{7}{|c|}{ Table 1: Composition of prepared ATO transdermal patches } \\
\hline Formulation & $\begin{array}{c}\text { ATO } \\
\text { (mg) }\end{array}$ & $\begin{array}{c}\text { HPMC } \\
\text { (mg) }\end{array}$ & $\begin{array}{c}\text { PVP } \\
\text { (mg) }\end{array}$ & $\begin{array}{c}\text { RS100 } \\
(\mathbf{m g})\end{array}$ & $\begin{array}{c}\text { PEG400 } \\
\text { (mg) }\end{array}$ & $\begin{array}{c}\text { DMSO } \\
\text { (mg) }\end{array}$ & Patch \\
\hline F1 & 50 & 350 & 50 & - & 120 & 30 & F \\
\hline F2 & 50 & 300 & 100 & - & 120 & 30 & F \\
\hline F3 & 50 & 250 & 150 & - & 120 & 30 & F \\
\hline F4 & 50 & 200 & 200 & - & 120 & 30 & N.F \\
\hline F5 & 50 & 350 & - & 50 & 120 & 30 & F \\
\hline F6 & 50 & 300 & - & 100 & 120 & 30 & F \\
\hline F7 & 50 & 250 & - & 150 & 120 & 30 & F \\
\hline F8 & 50 & 200 & - & 200 & 120 & 30 & N.F \\
\hline
\end{tabular}

$\mathrm{F}=$ Formed

N.F $=$ Not formed

Area of the patch $=38.5 \mathrm{~cm}^{2}$

\begin{tabular}{|c|c|c|c|c|c|c|c|}
\hline Formula & $\begin{array}{l}\text { Thickness } \\
\text { (mm } \pm \text { SD) }\end{array}$ & $\begin{array}{l}\text { Weight } \\
\left(\mathrm{mg} / \mathrm{cm}^{2}\right)\end{array}$ & $\begin{array}{c}\text { Drug } \\
\text { content (mg/ } \\
\left.\mathrm{cm}^{2}\right)\end{array}$ & $\begin{array}{c}\text { Folding } \\
\text { endurance } \\
\text { (Value } \pm S D \text { ) }\end{array}$ & $\begin{array}{c}\text { Tensile } \\
\text { strength } \\
\left(\mathrm{kg} / \mathrm{cm}^{2} \pm \mathrm{SD}\right)\end{array}$ & $\begin{array}{c}\text { Moisture } \\
\text { absorption } \\
(\% \pm \text { SD) }\end{array}$ & $\begin{array}{c}\text { Moisture loss } \\
\quad(\% \pm \text { SD) }\end{array}$ \\
\hline F1 & $0.13 \pm 0.08$ & $18.98 \pm 0.66$ & $1.31 \pm .05$ & $98 \pm 5.7$ & $0.19 \pm 0.02$ & $4.83 \pm 0.39$ & $10.15 \pm 1.13$ \\
\hline $\mathrm{F} 2$ & $0.12 \pm 0.52$ & $18.52 \pm 0.12$ & $1.29 \pm 0.45$ & $90 \pm 9.4$ & $0.28 \pm 0.04$ & $3.54 \pm 0.45$ & $8.15 \pm 0.95$ \\
\hline F3 & $0.12 \pm 0.05$ & $18.25 \pm 0.41$ & $1.32 \pm 0.35$ & $88 \pm 10.8$ & $0.31 \pm 0.09$ & $3.11 \pm 0.15$ & $7.15 \pm 0.64$ \\
\hline F4 & N.F & N.F & N.F & N.F & N.F & N.F & N.F \\
\hline F5 & $0.12 \pm 0.32$ & $18.81 \pm 0.24$ & $1.31 \pm 0.61$ & $96 \pm 11.3$ & $0.21 \pm 0.03$ & $3.91 \pm 0.23$ & $9.03 \pm 0.88$ \\
\hline F6 & $0.11 \pm 0.43$ & $18.31 \pm 0.12$ & $1.30 \pm 0.25$ & $90 \pm 12.4$ & $0.24 \pm 0.08$ & $3.24 \pm 0.42$ & $8.45 \pm 0.55$ \\
\hline F7 & $0.11 \pm 0.22$ & $18.12 \pm 0.44$ & $1.32 \pm 0.55$ & $80 \pm 11.9$ & $0.27 \pm 0.07$ & $2.12 \pm 0.51$ & $6.32 \pm 0.36$ \\
\hline F8 & N.F & N.F & N.F & N.F & N.F & N.F & N.F \\
\hline
\end{tabular}

*N.F: Not formed 


\begin{tabular}{|c|c|c|c|c|}
\hline \multicolumn{5}{|c|}{ Table 3: Serum lipid profile following ATO administration. } \\
\hline Groups & $\begin{array}{c}\text { T. Chol } \\
\text { (mg/dl) }\end{array}$ & $\begin{array}{c}\text { HDL } \\
\text { (mg/dl) }\end{array}$ & $\begin{array}{c}\text { TG } \\
\text { (mg/dl) }\end{array}$ & $\begin{array}{c}\text { LDL } \\
\text { (mg/dl) }\end{array}$ \\
\hline $\begin{array}{c}\text { G1 } \\
\text { (Normal rats) }\end{array}$ & $114.36 \pm 4.87$ & $40.12 \pm 2.47$ & $75.7 \pm 1.94$ & $59.09 \pm 2.35$ \\
\hline $\begin{array}{c}\text { G2 } \\
\text { (Non treated hyperlipidemic rats) }\end{array}$ & $140.09 \pm 4.85^{*}$ & $34.54 \pm 1.48$ & $122.9 \pm 4.11^{*}$ & $80.97 \pm 3.88^{*}$ \\
\hline $\begin{array}{c}\text { G3 } \\
\text { (Orally treated hyperlipidimic rats } \\
\text { with 10mg/kg ATO) }\end{array}$ & $121.69 \pm 2.98^{* \times}$ & $38.34 \pm 1.18$ & $87.4 \pm 2.29^{* \times}$ & $65.86 \pm 3.44^{* \times}$ \\
\hline $\begin{array}{c}\text { G4 } \\
\text { (Transdermally treated hyperlipidimic } \\
\text { rats with patches No. II 10mg/kg } \\
\text { ATO) }\end{array}$ & $122.82 \pm 3.94^{* \times}$ & $36.19 \pm 1.39$ & $91.2 \pm 3.68^{* \times}$ & $68.88 \pm 4.37^{*} \$$ \\
\hline $\begin{array}{c}\text { G5 } \\
\text { (Transdermally treated hyperlipidimic } \\
\text { rats with patches No. II 20mg/kg } \\
\text { ATO) }\end{array}$ & $115.96 \pm 2.18^{*}$ & $38.05 \pm 2.51$ & $77.1 \pm 2.12^{* \times *}$ & $63.35 \pm 3.83^{* \times}$ \\
\hline
\end{tabular}

Values are given as mean $\pm \mathrm{SD}, \mathrm{n}=5 ; * P<0.001$ vs. $\mathrm{G} 1, x P<0.01$ vs. $\mathrm{G} 2, \& P<0.001$ vs. $\mathrm{G} 2, \$ P<0.05$ vs. G2, \#P<0.05 vs. G4.

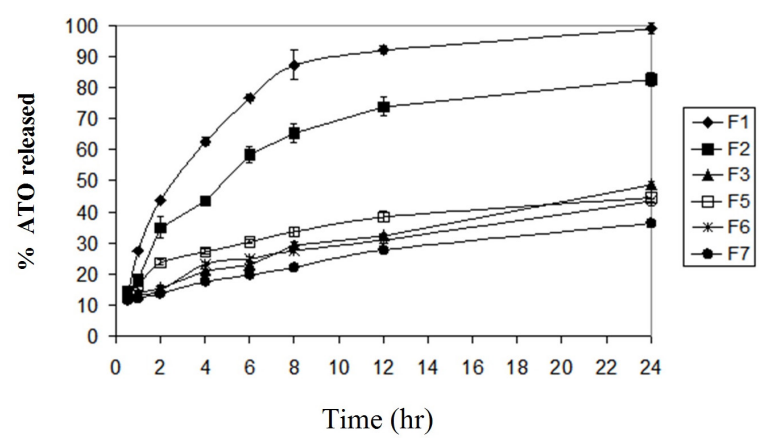

Figure 4: In vitro release profiles of ATO transdermal patches, in phosphate buffer $\mathrm{pH} 7.4$ at $37^{\circ} \mathrm{C}$. Data represented as mean $\pm \mathrm{SD}(n=3)$.

to the normal rats (G 1). Administration of $10 \mathrm{mg} / \mathrm{kg}$ ATO orally (G3) or in patches $10 \mathrm{mg} / \mathrm{kg}$ ATO and $20 \mathrm{mg} / \mathrm{kg}$, groups G4 and G5 respectively, significantly $(\mathrm{P}<0.01)$ reduced the total cholesterol in comparison to non treated group (G2). However there is no significant difference was found between (G3) and (G4). In addition, groups $G 3$, G4 and $G 5$ showed significant reduction on the TG level $(P<0.001)$ in comparison to the $\mathrm{G} 2$ group. Interestingly, there is no significant difference between G3 and G4, however there is significant difference between G4 and G5 concerning TG. Level $(P<0.01)$. LDL levels was reduced significantly $(P<0.01)$ in both groups G3 and G5 and significantly $(P<0.05)$ in group G4 in comparison to group G2. The levels of HDL showed insignificant changes in all groups compared to the non treated group G1, which could be attributed to the very short duration of treatment (only two weeks). The previous results opened the area for further investigations concerning the addition of several absorption enhancers that my result in more enhancing in the drug absorption.

\section{CONCLUSION}

ATO loaded transdermal patches were successfully formulated with different polymeric mixtures. ATO loaded patches showed good chemical and physical compatibility with accepted physicomechanical parameters. In vitro drug release of the prepared patches showed sustained release effect over $24 \mathrm{hr}$. In vivo evaluation of the best selected formulation (HPMC/PVP, 300:100) showed significant reduction of total cholesterol, triglycerides and LDL levels. Considering the study outcomes, ATO loaded patches showed promising results on laboratory animals that could motivate further research on human, in order to be used effectively and enhance patient's compliance.

\section{ACKNOWLEDGMENT}

This project was supported by deanship of scientific research, King Faisal University, grant number, DSR15782.

\section{ABBREVIATION USED}

ATO: Atorvastatin; CHDs: Coronary Heart Diseases; TC: Total Cholesterol; LDL: Low Density Lipoprotein; HDL: High Density Lipoprotein; HPMC: Hydroxypropyl Methylcellulose; RS100: Eudragit RS100; PVP: Polyvinylpyrrolidone; PEG:Polyethylene Glycol 400; FTIR: Fourier Transform Infra Red; DSC: Differential Scanning Calorimetry; TDDS: Transdermal Drug Delivery System; DMSO: Dimethyl Sulfoxide 


\section{REFRENCES}

1. Neil HA, Mant D, Jones L, Morgan, B, Mann JI. Lipid screening: is it enough to measure total cholesterol concentration? BMJ : British Medical Journal. 1990;301(6752): 584-587.

2. Jackson R, Beaglehole R. Evidence-based management of dyslipidemia. Lancet. 1995;346(8988): 1440-1442.

3. Shamsuddin, MF, Shahid HA, Javed A. Atorvastatin solid dispersion for bioavailability enhancement. J Adv Pharm Technol Res. 2016;7(1): 22-26.

4. Ankush C, Avtar CR, Geeta A, Virender K, Foziyah Z. Development and characterization of an atorvastatin solid dispersion formulation using skimmed milk for improved oral bioavailability. Acta Pharmaceutica Sinica B. 2012;2(4): 421-428.

5. Di Stasi SL, MacLeod TD, Winters JD, Binder-Macleod SA. Effects of Statins on Skeletal Muscle: A Perspective for Physical Therapists. Physical Therapy. 2010;90(10):1530-1542.

6. Subedi RK1, Oh SY, Chun MK, Choi HK. Recent advances in transdermal drug delivery. Arch Pharm Res. 2010;33(3):339-51.

7. Pastore MN, Kalia YN, Horstmann, M, Roberts MS. Transdermal patches: history, development and pharmacology. British Journal of Pharmacology. 2015;172(9): 2179-2209.

8. Londhe VY, Umalkar KB. Formulation Development and Evaluation of Fast Dissolving Film of Telmisartan. Indian Journal of Pharmaceutical Sciences. 2012;74(2): 122-126.

9. Semalty M, Semalty A, Kumar G. Formulation and Characterization of Mucoadhesive Buccal Films of Glipizide. Indian Journal of Pharmaceutical Sciences. 2008;70(1):43-48.

10. Saoji SD, Atram SC, Dhore PW, Deole PS, Raut NA, Dave VS. Influence of the Component Excipients on the Quality and Functionality of a Transdermal Film Formulation. AAPS PharmSciTech. 2015;16(6):1344-1356.

11. Alagusundaram M, Chetty CM, Dhachinamoorthi D. Development and evaluation of novel-trans-buccoadhesive films of Famotidine. Journal of Advanced Pharmaceutical Technology \& Research. 2011; 2(1): 17-23.
12. Prajapati ST, Patel CG, Patel CN. Formulation and Evaluation of Transdermal Patch of Repaglinide. ISRN Pharmaceutics. 2011;2011:651909.

13. Khan FN, Dehghan MHG. Enhanced Bioavailability of Atorvastatin Calcium from Stabilized Gastric Resident Formulation. AAPS PharmSciTech. 2011;12(4): 1077-1086.

14. Kumar L, Reddy MS, Shirodkar RK, Pai GK, Krishna VT, Verma R. Preparation and Characterisation of Fluconazole Vaginal Films for the Treatment of Vaginal Candidiasis. Indian Journal of Pharmaceutical Sciences. 2013;75(5): 585-590.

15. Mokhtar M, Shehata TM. The enhancement of transdermal permeability of water soluble drug by niosome-emulgel combination. Drug.Del. Sci. Tech. 2012;22(1): 353-359.

16. Zargar BA, Masoodi MH, Ahmed B, Ganie SA. Antihyperlipidemic and Antioxidant Potential of Paeonia emodi Royle against High-Fat Diet Induced Oxidative Stress. ISRN Pharmacology. 2014;2014:182362.

17. Allain CC, Poon LS, Chan CS, Richmond W, Fu PC. Enzymatic determination of total serum cholesterol. Clin Chem. 1974;20(4): 470-475.

18. Fossati P, Prencipe L. Serum triglycerides determined colorimetrically with an enzyme that produces hydrogen peroxide. Clin Chem., 1982;28(10): 2077-2080.

19. McGowan MW, Artiss JD, Strandbergh DR, Zak B. A peroxidase-coupled method for the colorimetric determination of serum triglycerides. Clin Chem. 1983;29(3): 538-542.

20. Friedewald WT, Levy RI. Fredrickson DS. Estimation of the concentration of low-density lipoprotein cholesterol in plasma, without use of the preparative ultracentrifuge. Clin Chem. 1972;18(6): 499-502.

21. Adhikari SNR, Nayak, BS, Nayak AK, Mohanty B. Formulation and Evaluation of Buccal Patches for Delivery of Atenolol. AAPS PharmSciTech. 2010;11 (3): 1038-1044.

22. Arora P, Mukherjee B. Design, development, physicochemical, and in vitro and in vivo evaluation of transdermal patches containing diclofenac diethylammonium salt. J Pharm Sci. 2002;91(9): 2076-89.

\section{SUMMARY}

- Atorvastatin loaded transdermal patches were successfully formulated with different polymeric mixtures.

- Atorvastatin loaded patches showed good chemical and physical compatibility with accepted physicomechanical param $\neg$ eters.

- In vitro drug release of the prepared patches showed sustained release effect over $24 \mathrm{hr}$.

- In vivo evaluation of the best selected formulation (HPMC/PVP, 300:100) showed significant reduction of total cholesterol, triglycerides and LDL levels.

- Atorvastatin loaded patches showed promising results on laboratory animals that could motivate further research on human.

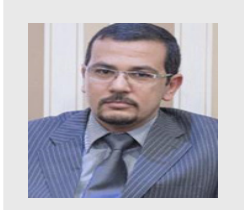

Dr. Tamer M. Shehata, is currently an associate professor of pharmaceutics and industrial pharmacy, college of clinical pharmacy, King Faisal University, KSA, and faculty of pharmacy, zagazig university, Egypt. Dr. Shehata, obtained his PhD on 2009 from faculty of pharmacy, Okayama university, JAPAN. Dr Shehata is interested in Drug Delivery Systems, Drug Targeting, Pharmacokinetics and Nanoparticls. He published several articles in highly reputed scientific journals, and he is reviewer in many journals.

Cite this article: Shehata TM, Mohafez OMM, Hanieh HN. Pharmaceutical Formulation and Biochemical Evaluation of Atorvastatin Transdermal Patches. Indian J of Pharmaceutical Education and Research. 2018;52(1):54-61. 